\title{
Smart learning environments for a smart city: from the perspective of lifelong and lifewide learning
}

\author{
Rongxia Zhuang, Haiguang Fang, Yan Zhang, Aofan Lu and Ronghuai Huang*
}

\author{
* Correspondence: \\ huangrh@bnu.edu.cn \\ Smart Learning Institute of Beijing \\ Normal University, Beijing, China
}

\begin{abstract}
In the perspective of lifelong learning, lifewide learning and learning society, learning environments have expanded from schools to a more broader space, and even to the whole city. School, family, community, workplace, and museum can be regarded as typical learning environments in a smart city. But few research about learning environments had been found on the combination of schools, families, communities and other learning situations. The purpose of this paper is to describe and analyze the characteristics of typical learning environments in smart cities, as well as the relationship of these learning environments. A mixed survey was carried out, a secondary analysis of statistical data of 68 cities was conducted, and a telephone survey with a sample of 13,600 people in 68 cities was used for data collection. It was found that there were significant differences in the development levels of five typical learning environments in smart cities, i.e., school, family, community, workplace, and museum learning environments. Some relations among the five typical learning environments were found.School had high relationship with community and museum learning environments. Family was strongly correlated with workplace and museum learning environments. Community was associated with museum, family, and school learning environments, but no significant relation existed between participation in community activities and workplace learning. As a public learning space, museum was related to all other learning environments. Further research should be taken to explore the reasons behind these correlations and their influencing factors.
\end{abstract}

Keywords: Smart learning environments, School learning environment, Family learning environment, Community learning environment, Workplace learning environment, Museum learning environment

\section{Background}

At present, there is not a uniform agreement on the meaning of a learning environment. Initially, people had focused on the definition of the static view of the physical environment ( $\mathrm{Gu}, 2014)$. Hannafin argued that a learning environment could be seen as an ecology, which included teachers, learners, teaching materials, evaluation, technology, and so on, and there were interactions among these components (Zheng \& Ma, 2010). Fraser (2012) stated that "the learning environment refers to the social, psychological and pedagogical contexts in which learning occurs and which affect student achievement and attitudes." They all emphasized the interaction between the learners and their environments.

(c) The Author(s). 2017 Open Access This article is distributed under the terms of the Creative Commons Attribution 4.0 International License (http://creativecommons.org/licenses/by/4.0/), which permits unrestricted use, distribution, and reproduction in any medium, provided you give appropriate credit to the original author(s) and the source, provide a link to the Creative Commons license, and indicate if changes were made. 
Learning environments should be regarded as important parts of a city, even in a smart city. But there is no clear definition of smart city (Nam \& Pardo, 2011; Neirotti, Cagliano, Mangano, \& Scorrano, 2014). Hollands (2008) stated smart city as an "urban labeling" phenomenon. Researchers tried to define smart city in different aspects, such as dimensions of technology, people, and institutions (Nam \& Pardo, 2011). The typical technology-oriented definition was "an instrumented, interconnected and intelligent city" by Harrison et al. from IBM (Harrison et al., 2010). Another definition of smart city was people-oriented. Paskaleva (2011) viewed smart cities as "people-based, human and progressive in their deployment of digital technologies, not to hardwire themselves, but instead to be socially inclusive in using them to foster good governance and create services capable of improving the quality of life." Finally, the governance-oriented definition of smart city refers to the administrative and organizational aspects of the city. Relatively, smart city is a new concept and new mode to promote the wisdom of urban planning, construction, management, and service by using the Internet, cloud computing, big data, geospatial information integration and other new generation information technology (National Development and Reform Commission, 2014). In general, smart city is under a widespread use of Information and Communication Technologies (ICT), which help cities better utilize the resources in different urban domains (Neirotti, Cagliano, Mangano, \& Scorrano, 2014). In the Dual-core framework of smart cities, proposed by Huang et al. (2015), the construction of smart cities on the micro level focuses on creating environment livable for the citizens, while on the macro level focuses on creating innovative developing environment, which are the two cores of smart cities' construction. Advocating "smart learning" plays a cultural leading role for stimulating vitality for urban innovation, and it also provides scientific support for citizens' livable experiences (Huang et al., 2015).

The concept of lifelong learning is well established (Candy, 1991), and lifewide learning can be seen as a concept in the paradigm of lifelong learning (Jackson, 2011). Swedish National Agency for Education (2000) points out that two dimensions can be used to describe the concept of lifelong learning, "the lifelong dimension represents what the individual learns throughout the whole life-span", and "the lifewide dimension refers to the fact that learning takes place in a variety of different environments and situations, and is not only confined to the formal educational system" . Lifewide learning covers formal, non-formal, and informal learning (National Agency for Education, 2000; Clark, 2005). Formal learning is always organized and structured, and has learning objectives, which takes place in education and training institutions. From the learner's point of view, it is intentional and typically leads to diplomas and qualifications. (Cedefop, 2014; Werquin, 2010; Singh, M., \& Singh, M., 2012). Informal learning is never organized. It has no set objective regarding learning outcomes, and is unintentional from the learner's perspective. It occurs in daily life, in the family, in the workplace, and so on (Cedefop, 2014; Werquin, 2010). Non-formal learning is preferable as the contrast to formal learning, which can also be structured according to educational and training arrangements, but more flexible (Eraut, 2011; Singh, M., \& Singh, M., 2012). Lifewide learning includes not just learning in formal contexts, but also learning in different contexts such as at home, in school, workplace, community, and others (Desjardins, 2003; Cambridge, 2008). According to it, smart learning could happen in school, family, community, workplace, museum, and others. Across people's 
life span, most of their learning happens in informal learning environments (Banks, $\mathrm{Au}$, Ball, Bell, Gordon, Gutiérrez, \& Nasir, 2007).

Beijing Declaration on Building Learning Cities-Lifelong Learning for All: Promoting Inclusion, Prosperity and Sustainability in Cities (Yi, 2014), has proposed some important measures to promote the building of a learning city, such as "promoting inclusive learning in the education system, revitalizing learning in families and communities, facilitating learning for and in the workplaces, and fostering a culture of learning throughout life" and others. The declaration emphasizes the importance of formal, non-formal and informal learning, and also implies that in the context of building learning cities, the research on learning environments should be expanded from schools to different environments, such as families, communities, and workplaces. It is necessary to take a view of the whole city, and to inspect the supportive roles of various types of learning environments on citizens' learning.

The construction and development of the learning environments in a city provide important supports for realizing a learning city, and important contents of a smart city. China has carried out the pilot work of building smart cities, and more than 400 cities have proposed the idea of smart cities or are constructing them (Bao, 2014). Recently, the focus of the smart city is not only on the construction of environment but also on the human infrastructure in the city (Nam \& Pardo, 2011). However, most of the existing learning environments researches focus on schools with some focusing on families, communities or workplaces. However, there is little empirical research of comprehensive survey on a city's different types of learning environments as a whole, and from the view of citizens in a smart city.

Therefore, this paper aims to describe and analyze the characteristics of typical learning environments in smart cities, as well as the correlations between these typical learning environments. The questions addressed in this study are 1 . What are the characteristics of typical learning environments in smart cities? 2. Are there correlations among the five typical learning environments, i.e., school, family, community, workplace and museum learning environment? If so, what do such correlations imply?

\section{Methods}

Research framework

Learning environments

Groups of different age stages have different development tasks and activities. In infancy, development activities include games and interactions with parents and others. In childhood and adolescence, developmental tasks include accepting formal education, developing knowledge skills and concepts, and developing the relations with parents, companies, and teachers. In adulthood, development tasks include career choice, adaption, and development, constructing and maintaining families. In elder period, development tasks include adapting to retirement and family changes and establishing contact with other elders (Lin, 2002).

As mentioned above, there are differences in activities depending on ages. From a certain perspective, relevant groups can reflect the characteristics of lifelong learning. They could be divided roughly into infant, young students (children and adolescent period), in-service personnels (adult period, and this period also includes students in 
higher education institutions in this paper), and retirees (elder period). Main activity fields can reflect the characteristics of lifewide learning to a certain extent, they could include families, schools, communities, workplaces, public places, and so on. Shown in Table 1.

Based on the Fraser's definition of learning environment and others, in this study, learning environments can be interpreted as the specific space where people perform learning activities. In different learning environments, people with similar development tasks and characteristics may interact with the surrounding factors in the learning process. People may also make use of the content resources, technical tools, learning methods, and the community with relationship, which can be the general background of the physical and social environment context.

Learning environments refers to the diverse physical locations, contexts, and cultures, in which students learn, they can be such as classrooms, workplaces, labs, museums, natural sites, means of transport, and home (Koper, 2014). Thus, learning environments in a city mainly include school learning environment, family learning environment, community learning environment, workplace learning environment and public place learning environment (museum learning environment is taken to represent for the public place learning environment in this research). These learning environments give supports to school education, family education, and social learning. They constitute the school education system funded by government and the city education system funded by society, providing supports for citizens' formal education, non-formal education and informal learning (see Fig. 1). Formal and non-formal education often happen in schools and some institutes, but non-formal learning may include learning activities that happen in the workplace, the local community and everyday life, and informal learning are on a "self-directed, family-directed, or socially-directed basis" (UNESCO, 2015). In Fig. 1, studying at school can manifest itself in learning in classrooms, campuses, and school districts.

\section{Smart learning environments}

Many scholars have put forward the idea of smart learning environments. Chin (1997) stated that smart learning environments are based on information communication technology, centered on learners, and with the following characteristics: the environment can adapt to the learning style and learning ability of diverse learners; can support the learners for lifelong learning; can support the learners for their development. Koper (2014) points out that smart learning environments are physical environments, which are improved to promote better and faster learning. Smart learning environment is a high level of digital environment, and can support "easy, engaged, and effective learning" in any place, at any time, in any way, and with any pace, which can also actively

Table 1 Main activity fields for different groups

\begin{tabular}{|c|c|c|c|c|c|}
\hline Groups & Families & Schools & Communities & Workplaces & Public places \\
\hline infants & $\sqrt{ }$ & & $\sqrt{ }$ & & $\sqrt{ }$ \\
\hline young students (children and adolescent period) & $\sqrt{ }$ & $\sqrt{ }$ & $\sqrt{ }$ & & $\sqrt{ }$ \\
\hline in-service personnels (adult period) & $\sqrt{ }$ & & $\sqrt{ }$ & $\sqrt{ }$ & $\sqrt{ }$ \\
\hline retirees (elder period) & $\sqrt{ }$ & & $\sqrt{ }$ & & $\sqrt{ }$ \\
\hline
\end{tabular}




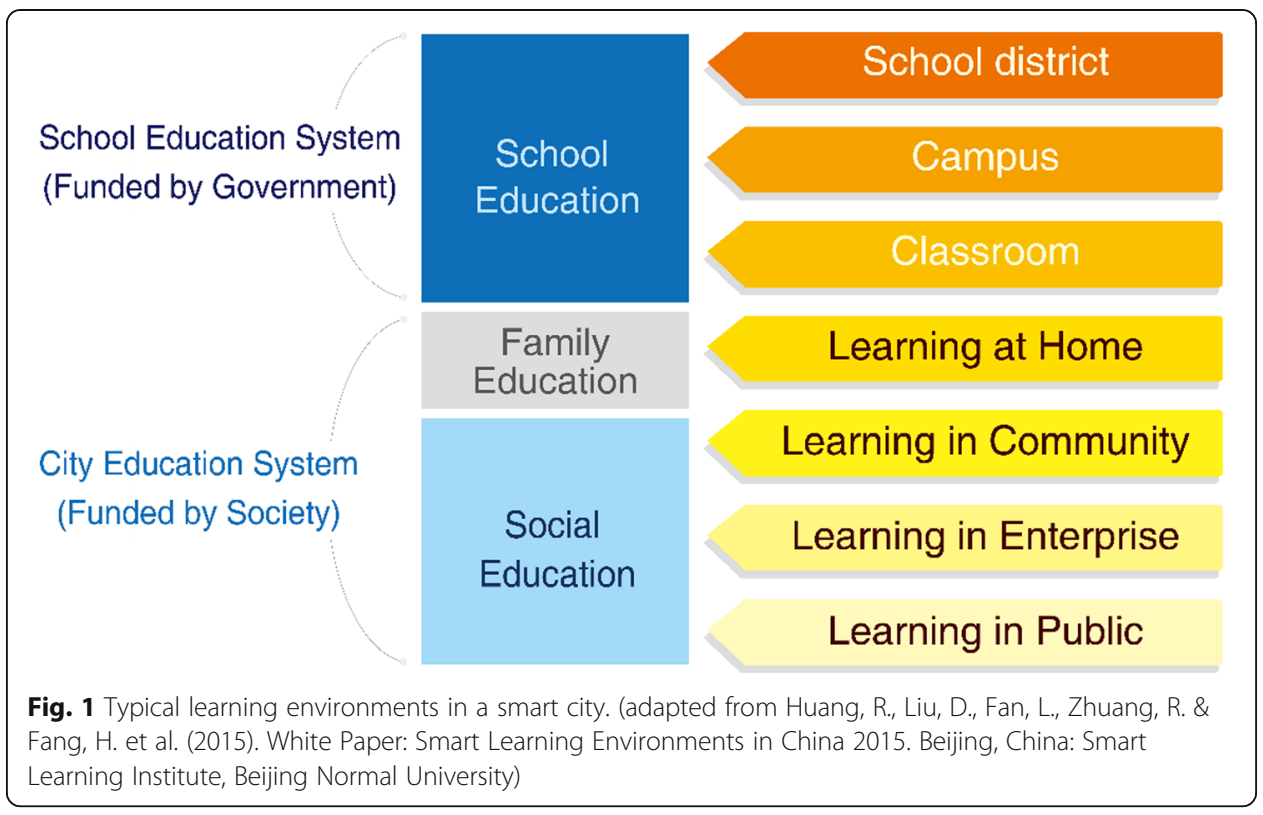

provide the necessary learning guidance, hints, supportive tools or learning suggestions for learners (Huang, Yang, \& Hu, 2012; Hwang, 2014).

Accordingly, smart learning could happen in school, family, community, workplace, museum and other environments in a city. The following is a brief analysis of these typical learning environments in smart cities.

\section{School learning environment}

During the whole life, school education gives people an overall, systematic and in-depth influence, and this period is an important process for learning and self-shaping of people (Wang, 2007). There are several instruments used in prior research to assess perceptions of classroom learning environment. The implication from prior research is that students' outcomes might be related to perceptions of classroom learning environment; in other words, students' achievement might be improved by creating better classroom learning environments (Fraser, 1986; Madu, 2010; Tas, 2016). Also, with integrating technology into education, growing number of researchers have focused on smart classroom learning environment and new forms of classroom learning environment like flipped classroom learning environment in recent years (Butzler, 2014; Jena, 2013).

\section{Family learning environment}

Family, as the first group of individuals, provides the most basic conditions for people's socialization (Wang, 2007), and is the basic field of people's social life. Family learning environment is also the basic learning environment for people. Family learning environment consists of a series of characteristics, including language stimulation, learning materials available at home, such as books and computers, as well as parenting behaviors, such as engaging children in learning activities and providing children with learning experiences (Bradley \& Caldwell, 1995). In addition, People of all ages can study at home to support his school learning, work, personal or family development, etc. Although family learning environment runs through a person's whole life, present researches 
pay more attention to the influence of family to children's cognitive abilities, learning performances and socio-emotional development (Melhuish et al., 2009; Foster et al., 2005), and that lacking research focus on other age groups.

\section{Community learning environment}

Community is the basic social living unit and the living base for majority social members, with multiple functions including politics, economy, culture and social management (Zhou, 2002). Communities play important roles on supporting learning and teaching that occur outside of schools, and the cultural education activities in communities, which have significant influence on the teenagers, the adults, and the elders. People in community learning environment can develop their individuals' knowledge, skills, confidence and capacity for life-long learning, as well constant services to the community (James, etc., 2012).

\section{Workplace learning environment}

The development of work tasks, the promotion of performance, the workplace training and so on, have an important role in promoting individual development of in-service staffs, and workplace learning environment is one of the important fields for adult learning activities. Watkins and Marsick (1993) suggested that key components of the workplace environment include creating continuous learning opportunities, promoting equity and dialogue, supporting individuals in maintaining an openness towards new experiences and reflection, and translating the learning into practice, encouraging team learning and collaboration, empowering people towards

a collective vision and connecting the organization to its environment. Zhao and Zhu (2015) considered that new technology has very important value to workplace learning, due to eliminating the conflict between working time and learning time, and benefits employees proceed informal learning and form the good habit of learning anytime and anywhere.

\section{Museum learning environment}

In public places, people can conduct multiple social activities such as working, learning, culture, social communication, entertainment, sports, rest and traveling, and public place learning environment is the important constituting part of learning environments for citizens. It is a window for reflecting the social material conditions and spirit civilization of a country or a nation. In this study, museum learning environment represents the learning environment in public places. We use "museum" as a generic term that includes all kinds of science museums, historical museums, planetariums, and other interpretative centers for learning. Museums have become an integral part of the broader learning and provide education to the public that called museum learning, which playing a critical role in lifelong learning as well educational leisure (Ahmad et al., 2013). Museum learning is an important research topic in the field of informal learning. Currently, research on technology-assisted museum learning focuses on developing a learner-centered method and applying technology to assist learners in exploring and learning in a museum (Wishart \& Triggs, 2010; Hou et al., 2014). 
The assessment framework and indicators system

Five typical learning environments provide the space and atmosphere for people to learn in a city, which is essential for cultivating creative talents to cope with all the innovations in the smart city. Therefore, it is important for us to understand the typical learning environments. Based on the above analysis, an assessment framework and indicators system was constructed. In the indicators system, there is an indicator for each type of learning environment, and each indicator has some sub-level indicators related to it, shown as in Table 2.

For school learning environment, computer resource allocation in primary and middle schools, multimedia classrooms, digital resource of primary and middle schools were selected as sub-level indicators for the school learning environment indicator. The main technical indicators for basic facilities construction as usually are the proportion of the number of students and the number of computers, the proportion of the number of teachers and the number of computers, network coverage, network equipment, multimedia classrooms, and so on (Liu et al., 2014; Fang, 2007; Jiang et al., 2008).

For home learning environment, family digital devices, family book possession, and satisfaction with family learning environment were selected as sub-level indicators for the home learning environment indicator. It has some similarities with the Home Observation of the Measurement of the Environment, which is formed by eight subscales: Encouragement of Maturity, Emotional Climate of the Home, Aspects of the Physical Environment, and so on (Bradley et al., 1988).

For community learning environment, utilization of learning places in community, utilization of community's information platform, participation of learning activities in community, and development of community education were chosen. In a research for the evaluation of the effect of learning community construction (Sun, Wang, \& Chen,

Table 2 Indicators for the five typical learning environments in smart cities

\begin{tabular}{|c|c|}
\hline Indicator & Sub-level indicators(Abbreviation) \\
\hline \multirow[t]{3}{*}{ School learning environment indicator } & $\begin{array}{l}\text { Computer resource allocation in primary and middle } \\
\text { schools (ComRes) }\end{array}$ \\
\hline & Multimedia classrooms in primary and middle schools (MulClas) \\
\hline & Digital resource of primary and middle schools (DigRes) \\
\hline \multirow[t]{3}{*}{ Family learning environment indicator } & Family digital devices (FamDig) \\
\hline & Family book possession (FamBook) \\
\hline & Satisfaction with family learning environment (FamSat) \\
\hline \multirow[t]{4}{*}{ Community learning environment indicator } & Utilization of learning places in community (PlaceCom) \\
\hline & Utilization of community's information platform (PlatCom) \\
\hline & Participation of learning activities in community (ActCom) \\
\hline & Development of community education (DevCom) \\
\hline \multirow[t]{3}{*}{ Workplace learning environment indicator } & Internet environment in workplace (IntWork) \\
\hline & Learning engagement in workplace (EngWork) \\
\hline & Online learning in workplace (OnIWork) \\
\hline \multirow[t]{3}{*}{ Museum learning environment indicator } & Number of museums (NumMus) \\
\hline & Utilization of the museum for learning (UtilMus) \\
\hline & Informationization in museum (InfMus) \\
\hline
\end{tabular}


2007), people can evaluate the effectiveness of the learning community construction from the organizational management, carrier design, learning activities, and the achievement of the construction.

For workplace learning environment, we chose Internet environment, learning engagement, and online learning as sub-level indicators for workplace learning environment. By a review of the literature, Clarke pointed out the factors which influence workplace environment for learning outcomes: supportive learning and development infrastructure; particular types of learning opportunities; empowerment and effective communication; support for reflection and job challenge; and support for learning transfer (Clarke, 2005).

For museum learning environment, the number of museums, utilization of the museum for learning, and informationization in museum as sub-level indicators for museum learning environment indicator were chosen. Referring to the characteristics of learning environment proposed by Chuang and Tsai, Xu et al. have constructed a evaluation structure in digital venuesof three dimensions: study subject, situation, and digital exhibits (Chuang \& Tsai, 2005; Tsai, 2008; P. Tsai, C. Tsai, \& Hwang, 2012; Xu \& Zhang, 2016).

\section{Research method}

In this paper, a mixed survey research was used to evaluate typical learning environments in 68 cities in China. Based on the regional distribution, economic level, urban population, data availability and other factors, 68 cities were selected, including Beijing, Shanghai, Tianjin, Chongqing, Guangzhou, and so on. Secondary data analysis and telephone interview were used for data collection.

Secondary analysis refers to some re-analyses of data collected by other researchers or organizations originally, including the analysis of datasets collated from a variety of sources to create time series or area-based datasets (Hakim, 2000). In this study, Data was collected from government publications for indicator of computer resource allocation in primary and middle schools (ComRes), multimedia classrooms (MulClas), digital resource of primary and middle schools (DigRes), development of community education (DevCom), and the number of museums (NumMus). The government publications include China Statistical Yearbook, ${ }^{1}$ China Education Statistics, ${ }^{2}$ China City Statistical Yearbook, ${ }^{3}$ and several kinds of statistical yearbooks related to the 68 cities. ${ }^{4}$

As a part of the survey, 16 questions were developed according to the indicators, i.e. indicator of family digital devices (FamDig), family book possession (FamBook), satisfaction with family learning environment (FamSat), utilization of learning places in community (PlaceCom), utilization of community's information platform (PlatCom), participation of learning activities in community (ActCom), Internet environment in workplace (IntWork), learning engagement in workplace (EngWork), online learning in workplace (OnlWork), utilization of the museum for learning (UtilMus), and informationization in museum (InfMus). The investigations were carried out from December 18, 2015, to February 29, 2016. Based on the age distribution of the population and other factors, with random sampling and convenient sampling methods, telephone interviews were conducted on citizens from 18 to 70 years old in 68 cities. Finally, 200 valid samples for each city were involved, and the total number of valid samples was 13,600. Table 3 shows the demographic of respondents. 
Table 3 Profile of Respondents

\begin{tabular}{llll}
\hline Measure & Category & Frequency & Percentage \\
\hline Gender & Male & 7681 & $56.5 \%$ \\
& Female & 5919 & $43.5 \%$ \\
& Total & 13,600 & $100 \%$ \\
Age & $18-35$ & 5892 & $43.3 \%$ \\
& $36-60$ & 6437 & $47.3 \%$ \\
& $61-70$ & 1271 & $9.4 \%$ \\
& Total & 13,600 & $100 \%$ \\
\hline
\end{tabular}

\section{Data analysis}

Based on the responses of citizens, some methods were used to calculate the indicator values of each city, such as ratio method, normalization using maximum value, equal-weight method, etc. According to the research questions, data was analyzed by descriptive analyses and correlation analyses. To describe the distributions of the values of five learning environment indicators, means, standard deviations and coefficients of variation were calculated. To analyze the correlations among all pairs of the five typical learning environments, and their sub-level indicators, correlations coefficients were calculated using the nonparametric Spearman rho statistic, and a significance level of $P<0.05$ (2-tailed) was applied. Data were analyzed by SPSS Statistics 20.0.

\section{Results}

In accordance with the descriptive analyses of five learning environment indicators, the distributions of value of family learning environment indicator and value of workplace learning environment indicator were relatively concentrated (the mean value was relatively high and with relatively small coefficient of variation); the distributions of value of community learning environment indicator and value of museum learning environment indicator were less concentrated; and the distribution of value of school learning environment indicator was mostly dispersed (see Table 4).

The correlations among the pairs of five learning environment indicators are also shown in Table 4. Tables 5, 6, 7, 8 and 9 demonstrate relations of corresponding specific indicators of each learning environment. Combined with multiple tables, the following sections describe the results in detail.

Table 4 Intercorrelations, Means, Standard Deviations, Coefficient of Variation for five learning environment indicators $(N=68)$

\begin{tabular}{lllllllll}
\hline Indicator & 1 & 2 & 3 & 4 & 5 & $\mathrm{M}$ & $\mathrm{SD}$ & $\mathrm{CV}$ \\
\hline 1.School & - & .213 & $.419^{* *}$ & .221 & $.631^{* *}$ & .3701 & .1805 & .4876 \\
2.Family & - & - & $.442^{* *}$ & $.783^{* *}$ & $.641^{* *}$ & .7860 & .0902 & .1147 \\
3.Community & - & - & - & $.286^{*}$ & $.615^{* *}$ & .5755 & .1565 & .2720 \\
4.Workplace & - & - & - & - & $.522^{* *}$ & .7152 & .0933 & .1305 \\
5.Museum & - & - & - & - & - & .5766 & .0983 & .1705 \\
\hline
\end{tabular}

${ }^{*} p<.05$, two-tailed. ${ }^{* *} p<.01$, two-tailed 


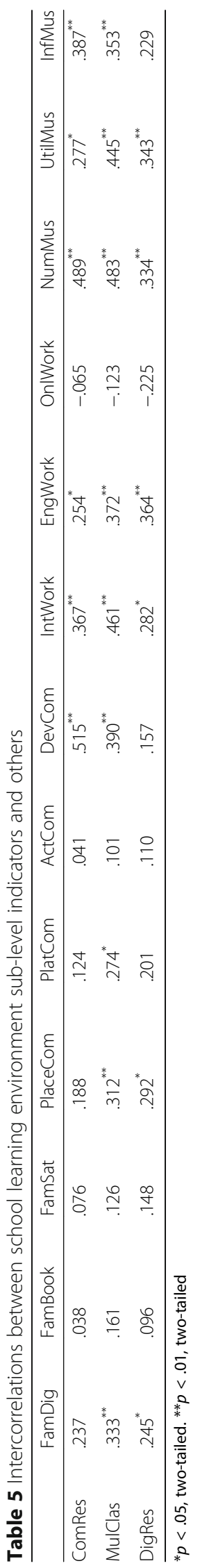




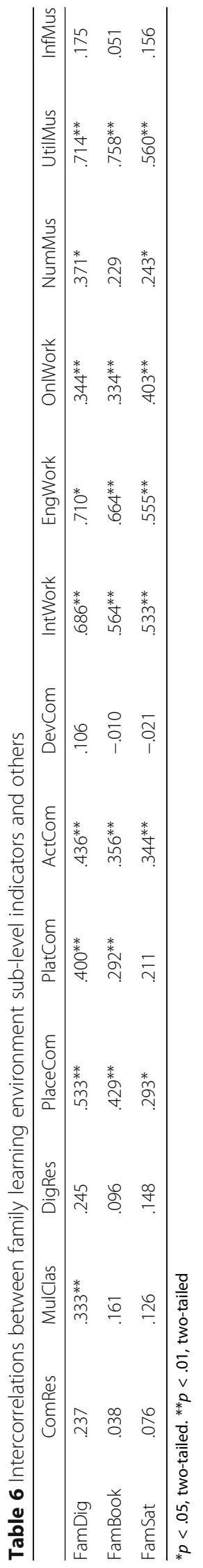




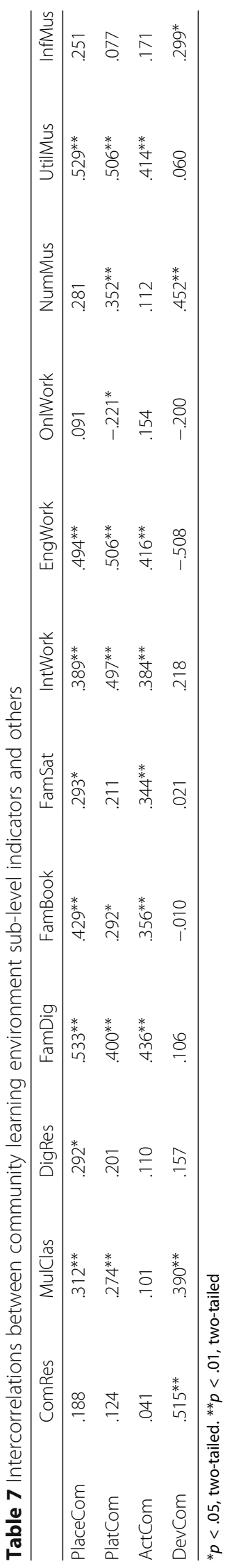




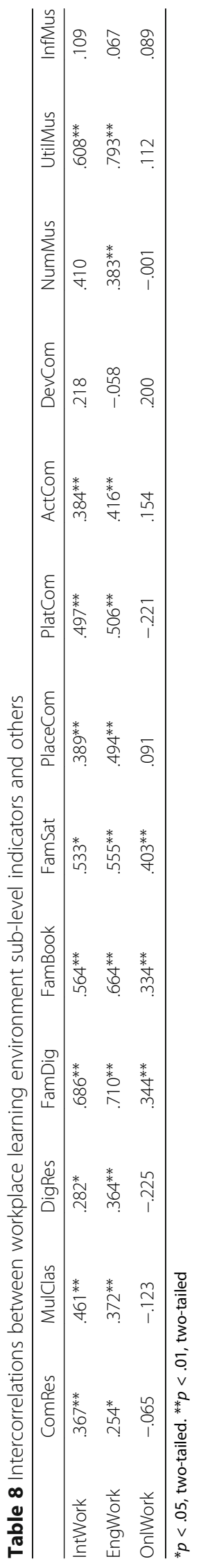




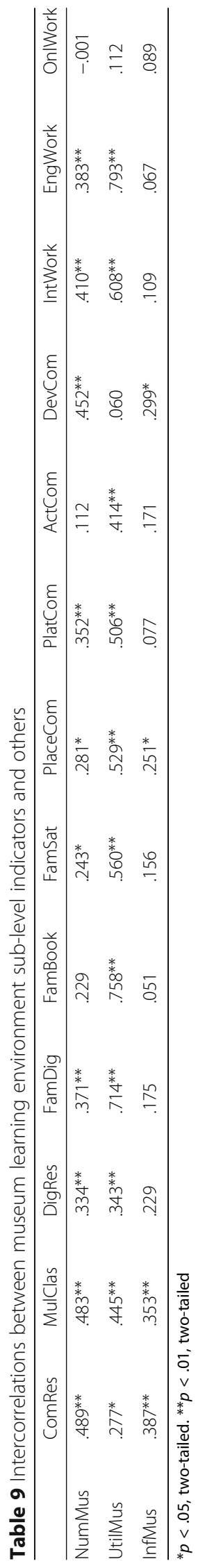




\section{School learning environment}

The school learning environment indicator had the strongest correlation with museum learning environment indicator (rho $=.631, p<.01$ ), then with community learning environment indicator (rho $=.419, p<.01$ ) (see Table 4 ). Table 5 shows the correlations among three sub-level indicators of school learning environment and thirteen sub-level indicators of other four learning environments. The most three correlative relations were computer resource allocation in primary and middle schools (ComRes) with development of community education (DevCom) (rho $=.515, p<.01$ ), computer resource allocation in primary and middle schools(ComRes) with the number of museums (NumMus) in a city (rho $=.489, p<.01$ ), and multimedia classrooms in primary and middle schools (MulClas) with the number of museums (NumMus) in a city (rho $=.483, p<.01$ ).

\section{Family learning environment}

The strongest correlation was between the family learning environment indicator and the workplace learning environment indicator ( $r h o=.783, p<.01$ ). The family learning environment indicator was also significantly correlated with the museum learning environment indicator ( $\mathrm{rho}=.641, p<.01$ ) (Table 4). In consequence, these three specific sub-level indicators of family learning environment were all significantly correlated with those three sub-level indicators of workplace learning environment (see in Table 6). Also, family digital devices (FamDig) (rho $=.714, p<.01$ ), family book procession (FamBook) (rho $=.758, p<.01$ ) and satisfaction with family learning environment $($ FamSat $)($ rho $=.560, p<.01)$ were strongly correlated with utilization of the museum for learning(UtilMus).

\section{Community learning environment}

The community learning environment indicator was significantly correlated with school (rho $=.419, p<.01)$, family (rho $=.442, p<.01)$, workplace (rho $=.286, p<.05)$ and museum learning environment indicator (rho $=.615, p<.01$ ) (Table 4). As Table 7 shown, utilization of learning places in community(PlaceCom) was significantly correlated with family digital devices (FamDig) (rho $=.533, p<.01$ ), utilization of the museum for learning (UtilMus) (rho $=.529, p<.01$ ). Moreover, utilization of community's information platform (PlatCom) was correlated with learning engagement in workplace (EngWork) and utilization of the museum for learning (UtilMus), these two coefficients all up to.506. Similarly, participation of learning activities in community (ActCom) was also correlated with learning engagement in workplace (EngWork) (rho $=.416, p<.01$ ) and utilization of the museum for learning (UtilMus) (rho $=.414, p<.01$ ), as well related to family digital devices (FamDig) (rho $=.436, p<.01$ ). The last sub-level indicator of community learning environment-development of community education (DevCom) and computer resource allocation in primary and middle schools (ComRes) were comparatively correlated with coefficient of .515 .

\section{Workplace learning environment}

We can acquire some information from Table 4 that there were significant correlations between workplace learning environment indicator and family learning environment indicator (rho $=.783, p<.01$ ), museum learning environment indicator (rho $=.522$, 
$p<.01$ ), community learning environment indicator (rho $=.286, p<.05$ ) respectively. According to Table 8, the sub-level indicators of workplace learning environment, i.e., Internet environment in workplace (IntWork) and learning engagement in workplace (EngWork), were significantly correlated with some sub-level indicators of family learning environment and museum learning environment, which were consistent with the former result.

\section{Museum learning environment}

The relations of museum learning environment indicator and other remaining learning environment indicators were closely correlative with ordinal coefficient .631, .641, .615 and .522 (Table 4). According to Table 9, the sub-level indicator of museum learning environment - number of museums (NumMus) was related closely to computer resource allocation in primary and middle schools (ComRes), multimedia classrooms(MulClas) and development of community education (DevCom). The other sub-level indicator, utilization of the museum for learning(UtilMus) had closer relations with learning engagement in workplace(EngWork), family book possession (FamBook), family digital devices (FamDig) at the same time.

\section{Discussion}

In perspective of lifelong learning and lifewide learning, smart learning environments for a smart city may include formal, non-formal and informal learning environments, such as school, family, community, workplace, and museum, etc. Citizen can learn in or across some types of these learning environments in a smart city. Correlations exist among these learning environments and their sub-level indicators.

1. The relations among the school and other learning environment: school learning environment is more closely associated with museum and community learning environment.

The highly correlated indicators and sub-level indicators, such as computer resource allocation, development of community education, the number of museums, and multimedia classrooms, may reflect the construction of a city's infrastructure, which is also closely related the development history of school learning environment. The revolution of switching traditional learning environment to digital learning environment focuses on the various infrastructure that can promote learners' learning (such as computers, network facilities, and various electronic devices) and construction of learning resources. Up to time of smart learning environments, attention had been paid to the construction of infrastructure too, but more emphasis should be put on utilizing proper instruments and technique in appropriate places and at the right time based on the needs of individual learners by analyzing their learning behavior, performance and their presence in the online and real world contexts (Hwang et al. 2008). Learning in the community or the museum is a supplement to the classroom learning, because some specific knowledge or skills are more easily acquired in community and museum. Learner's learning experiences in communities and museums are crucial to link school life and real life which is a vital reason why advocating of blending schools and communities and museums.

2. The relations among family and other learning environment: family learning environment is more closely associated with workplace and museum learning environment. 
Family learning environment relates with workplace and museum learning environment indicators more tightly. It can be found that the more digital equipment a family have, the more possible the person is to be able to adapt digital learning, the more attention he/she should pay to self-improvement in the workplace. The main reason may be the support of information technology which might lead some learning behaviors and learning habits in family learning environment into transfering to workplace learning environment.

Three sub-level indicators of family learning environment are significantly related to the utilization of the museum for learning indicator, which indicates that families with better family learning environment are more willing to access to museum. From the perspective of the smart city, a favorable family learning environment not only become the basis of making progress in the workplace for parents, but also as the driving force of expanding educational activities into museums for children. The past studies about the family learning environment almost all concerned about the impact on children, especially on children's growth (Anders et al., 2012; Becker, 2011; Foster et al., 2005). However, in this study, the results showed that the family learning environment also have a certain influence on parents' career development.

3. The relations among the community and other learning environment: community learning environment is more closely associated with museum, family, and school learning environments.

As a public place where people live, the community has a closer relation with other environments. This relation is reflected in the expenditure on public infrastructure and the participation of people learning activities. Community learning activities encourage residents to participate in which facilitate the link between individuals and communities with various forms and contents that be able to connect with other learning environments. The purpose of community learning is to help people of different ages and backgrounds acquire new skills, reconnect with learning, follow an interest, ready to enter the regular course (Sunderland City Council, 2016). For such purpose, the community learning environment can be closely connected with family and school learning environments. What's more, the enthusiasm of involving in community learning activities is related to museum learning activities.

4. The relations among the workplace and other learning environment: workplace learning environment is more closely associated with family and museum learning environment.

Staffs have an intimate association with family and museum learning environments. They are encouraged to learn and inspired during working. Workplace learning is recognized as a crucial occasion to develop various knowledge and skills which can provide opportunities to attain competence in problem-solving, as well as to acquire and share knowledge (Eraut, 2000). Hence, this type of learning pattern is easy to migrate to other environments, such as museum, families. With the progress of the society, the popularity of science and technology, the rapid development of smart city, staffs in the workplace are required to pay more attention to the usage of information technology which can also be used in family for operating digital devices, in other public environments for applying service platform and so on.

5. The relations among the museum and other learning environment: museum learning environment is related to all kinds of the learning environment. 
There is a significant correlation between the museum learning environment indicator and the family learning environment indicator. That shows that the informal learning in the family and the museum is increasingly recognized and valued by the citizens. Families are one of the most important visitors in the museum. Usually, adults are motivators of youngers' personal learning. Mother and father play different roles in museums, where mom is occupied in the logistical work of the visit and the father sees the museum as a "family business." Work on literacy and adult learning implied that a direction to "life-long learning" in the future life is closely related to the family (Ahmad et al., 2013).

There is a significant correlation between the museum learning environment indicator and the school learning environment indicator. Schools and museums are important places for teenagers to accept education, and this idea is accepted by parents and educators. According to American Alliance of Museums (2014), museums receive more than 55 million students a year in school groups. Also, scholars and researchers also carry out various attempts to combine museum education and school education they regard museum education as a bridge to connect school and society. The project "Urban Advantage" implemented by the New York government aimed to link classroom, family, and museum to promote carrying out inquiry teaching activities in secondary school. These will integrate multiple learning environments to facilitate learners' learning across contexts and enhance the relations among each learning environment.

Moreover, when ICT's gradually develop maturely either in the form of hardware or software in museum learning environment, it is an opportunity to accelerate collaboration among schools, families, communities, and workplaces to propel engagement and learning. In general, as a public learning space, the museum and other learning environments are interrelated strongly. On the one hand, museums show a distinct context for informal learning that undertakes a public responsibility for all parts of society (Head, 2006), on the other hand, it is a convictive evidence to further illustrate ubiquity learning and the breadth of learning.

\section{Conclusion and limitation}

Above all, the aim of learning environments in smart cities is to support citizens' smart learning, smart learning can provide strong support for citizens' life-long learning, which is also the key feature of self-evolution of the urban system. This paper conducts preliminary analysis on the characteristics of typical learning environments in smart cities from perspective of lifelong and lifewide learning. Research about learning environments are neither limited in formal situation nor an individual context, but expand to five environments, so that the relations among these typical learning environments have been detected. The results indicated that school, community, and museum learning environments are correlated basing on the demand for the construction of city's infrastructure; because of the possible transfer of learning habits and so on, family learning is more correlated with workplace and museum learning environments; as a public living space, community is associated with museum, family, and school learning environments, but no significant relation exists between participation in community activities and workplace learning; as a public learning space, museum is suitable for citizens of all ages, and it is related to all other learning environments. 
However, these relations should be interpreted deeply. Other factors which may influence learning environment, such as urban economic development levels and the development levels, have not been considered in this study. Meanwhile, citizens' factors are not to be neglected in some specific learning environments, but lack of thoughtfulness as well in this study. Therefore, further analysis will be conducted on these factors among various learning environments .

Additionally, smart learning is an important part of the construction of smart city. The indicators for the five typical learning environments in smart cities can reflect the status of the construction not only of a learning society but also of smart cities. And the result can provide some reference for the construction of smart city and smart learning environments.

\section{Endnotes}

${ }^{1}$ Data were available from http://www.stats.gov.cn/tjsj/ndsj/

${ }^{2}$ Data were available from http://www.moe.gov.cn/s78/A03/moe_560/jytjsj_2016/

${ }^{3}$ Yearbooks were published by China Statistics Press.

${ }^{4}$ Data were available from books in paper or Statistical Database of China's Economic and Social Development (http://tongji.cnki.net/kns55/index.aspx)

Authors' contributions

All Authors read and approved the final manuscript.

Competing interests

The authors declare that they have no competing interests.

\section{Publisher's Note}

Springer Nature remains neutral with regard to jurisdictional claims in published maps and institutional affiliations.

Received: 30 May 2017 Accepted: 4 October 2017

Published online: 30 October 2017

References

S Ahmad, MY Abbas, ZMY Wan, MZM Taib, Museum learning: Using research as best practice in creating future museum exhibition. Procedia-Soc Behav Sci. 105(2), 370-382 (2013)

American Alliance of Museums (2014). Building the Future of Education: Museums and the Learning Ecosystem. http://www.aam-us.org/docs/default-source/center-for-the-future-of-museums/building-the-future-of-educationmuseums-and-the-learning-ecosystem.pdf

Y Anders, H Rossbach, S Weinert, S Ebert, S Kuger, S Lehrl, et al., Home and preschool learning environments and their relations to the development of early numeracy skills. Early Childhood Research Quarterly 27(2), 231-244 (2012)

JA Banks, KH Au, AF Ball, P Bell, EW Gordon, K Gutiérrez, et al., Learning in and out of School in Diverse Environments: Life-Long, Life-Wide, Life-Deep (The LIFE Center and the Center for Multicultural Education, University of Washington, Seattle, 2007)

X Bao, More than 400 cities in China announced the construction of smart city. Securities Daily. p.1. (2014)

B Becker, Social disparities in children's vocabulary in early childhood: Does pre-school education help to close the gap. Br. J. Sociol. 62(1), 69-88 (2011)

RH Bradley, BM Caldwell, Caregiving and the regulation of child growth and development: Describing proximal aspects of caregiving systems. Dev. Rev. 15(1), 38-85 (1995)

RH Bradley, BM Caldwell, SL Rock, HM Hamrick, P Harris, Home observation for measurement of the environment: Development of a home inventory for use with families having children 6 to 10 years old. Contemp. Educ. Psychol. 13(1), 58-71 (1988)

KB Butzler, The Effects of Motivation on Achievement and Satisfaction in a Flipped Classroom Learning Environment (Doctoral dissertation, Northcentral University, 2014)

D Cambridge, Audience, integrity, and the living document: eFolio Minnesota and lifelong and lifewide learning with ePortfolios. Comput. Educ. 51(3), 1227-1246 (2008)

P Candy, Self-Direction for Lifelong Learning: A Comprehensive Guide to Theory and Practice (Jossey Bass, San Francisco, 1991)

Cedefop, Terminology of European Education and Training Policy: A Selection of 130 Terms, 2nd edn. (Publications Office, Luxembourg, 2014) 
KW Chin, Smart learning environment model for secondary schools in Malaysia: An overview. Retrieved from http://www. powershow.com/view/13d931-ZGY4M/Smart_Learning_Environment_Model_For_Secondary_Schools_in_Malaysia_ An_Overview_Making_a_difference_powerpoint_

SC Chuang, CC Tsai, Preferences toward the constructivist internet-based learning environments among high school students in Taiwan. Comput. Hum. Behav. 21(2), 255-272 (2005)

T Clark, Lifelong, life-wide or life sentence? Australian Journal of Adult Learning 45(1), 47-62 (2005)

R Desjardins, Determinants of literacy proficiency: A lifelong-lifewide learning perspective. Int. J. Educ. Res. 39(3), 205-245 (2003) M Eraut, Non-formal learning and tacit knowledge in professional work. Br. J. Educ. Psychol. 70, 113-136 (2000)

Y Fang, Strengthening standard research and promoting the development of education informationization in colleges and universities. Journal of e-education Research 6 (2007)

MA Foster, R Lambert, M Abbott, F McCarty, S Franze, A model of home learning environment and social risk factors in relation to children's emergent literacy and social outcomes. Early Childhood Research Quarterly 20(1), 13-36 (2005)

BJ Fraser, Classroom Learning Environments: Retrospect, Context and Prospect (Springer, Netherlands, 2012)

M Gu, (2014).Gu Mingyuan Education Lecture. Beijing:People Education Publishes.

C Hakim, Research design: Successful designs for social and economic research. Nature 4546, 1332-1333 (2000)

C Harrison, B Eckman, R Hamilton, P Hartswick, J Kalagnanam, J Paraszczak, P Williams, Foundations for smarter cities. IBM J. Res. Dev. 54(4) (2010)

B Head, PICO International (Malaysia) Sdn (Bhd, Museum Seminar, Malaysia National Museum, Kuala Lumpur, 2006)

RG Hollands, Will the real smart city please stand up? Intelligent, progressive or entrepreneurial. City 12(3), 303-320 (2008)

HT Hou, SY Wu, PC Lin, YT Sung, JW Lin, KE Chang, A blended mobile learning environment for museum learning. Educational Technology \& Society 17(2), 207-218 (2014)

R Huang, D Liu, L Fan, R Zhuang, H Fang, W Cheng, Y Jiao, White Paper: Smart Learning Environments in China 2015 (Smart Learning Institute of Beijing Normal University, Beijing, 2015) Retrieved October 21, 2016, from http://sli.bnu. edu.cn/a/yanjiuchengguo/yanjiubaogao/2016/0425/168.html

RH Huang, JF Yang, YB Hu, From digital learning environments to smart learning environments. Open. Education Research 1, 75-84 (2012)

GJ Hwang, Definition, framework and research issues of smart learning environments-a context-aware ubiquitous learning perspective. Smart Learning. Environments 1(1), 1 (2014)

GJ Hwang, CC Tsai, SJ Yang, Criteria, strategies and research issues of context-aware ubiquitous learning. J Educ Technol Soc. 11(2) (2008)

NJ Jackson, (2011). The lifelong and lifewide dimensions of living, learning and developing. In Jackson, N. J. (2011). Learning for a complex world: A lifewide concept of learning, education and personal development, Authorhouse.1-21.

P James, Y Nadarajah, K Haive, V Stead, Sustainable Communities, Sustainable Development: Other Paths for Papua New Guinea (University of Hawai'i Press, Honolulu, 2012)

PC Jena, Effect of smart classroom learning environment on academic achievement of rural high achievers and low achievers in science. International Letters of Social \& Humanistic. Sciences 3(3), 1-9 (2013)

D Jiang, Research on some Important Issues of Educational Informationization (Science Press, Beijing, 2008)

R Koper, Conditions for effective smart learning environments. Smart Learning. Environments 1(1), 1-17 (2014)

C Lin, Development Psychology (Zhejiang Education Publishing Press, Hangzhou, 2002)

$X$ Liu, Y Wang, X Wang, G Ren, J Jiao, Research on the development strategy of ict infrastructure in education in the process of educational informatization. Journal of Distance Education 2 (2014)

NE Madu, Associations between Teachers Interpersonal Behaviour, Classroom Learning Environment and Students Outcomes (Doctoral dissertation, Curtin University, 2010)

E Melhuish, J Belsky, AH Leyland, J Barnes, Effects of fully-established sure start local programmes on 3-year-old children and their families living in England: A quasi-experimental observational study. Child Care Health Dev. 35(2), 284-285 (2009)

T Nam, \& Pardo, T. A. (2011, June). Conceptualizing smart city with dimensions of technology, people, and institutions. In Proceedings of the 12th Annual International Digital Government Research Conference: Digital Government Innovation in Challenging Times (pp. 282-291). ACM.

National Agency for Education, Lifelong Learning and Lifewide Learning (Liber Distribution Publikationstjänst, Stockholm, Skolverket, 2000), pp. 1-46

National Development and Reform Commission, Guidance on promoting smart city development (Publication No. [2014]1770) (China, Beijing, 2014)

P Neirotti, A De Marco, AC Cagliano, G Mangano, F Scorrano, Current trends in Smart City initiatives: Some stylised facts. Cities 38, 25-36 (2014)

KA Paskaleva, The smart city: A nexus for open innovation? Intelligent Buildings International 3(3), 153-171 (2011)

M Singh, M Singh, Unesco guidelines for the recognition, validation and accreditation of the outcomes of non-formal and informal learning. Unesco Institute for Lifelong. Learning 11(33), 1631-1636 (2012)

W Sun, M Wang, L Chen, Research on assessing method for effectiveness of learning community. Journal of Hebei University of. Technology 36(2), 67-72 (2007)

Sunderland City Council (2016). Family, adult and community learning. http://www.sunderland.gov.uk/index. aspx?articleid $=660$.

Y Tas, The contribution of perceived classroom learning environment and motivation to student engagement in science. Eur. J. Psychol. Educ. 31, 1-21 (2016)

CC Tsai, The preferences toward constructivist internet-based learning environments among university students in Taiwan. Comput. Hum. Behav. 24(1), 16-31 (2008)

PS Tsai, CC Tsai, G Hwang, Developing a survey for assessing preferences in constructivist context-aware ubiquitous learning environment. J. Comput. Assist. Learn. 28(3), 250-264 (2012)

UNESCO, Rethinking Education: Towards a Global Common Good? (UNESCO Publishing, Paris, 2015)

R Wang, (2007). Huamn Behavior and Social Envirionment(2nd ed.). Shanghai: East China University of Science and Technology Press. 
KE Watkins, VJ Marsick, In Action: Creating the Learning Organization (American Society for Training and Development, Alexandria, 1993)

P Werquin, Recognising Non-formal and Informal Learning Outcomes, Policies and Practices: Outcomes, Policies and Practices (OECD publishing, 2010)

J Wishart, P Triggs, Museum scouts: Exploring how schools, museums and interactive technologies can work together to support learning. Comput. Educ. 54, 669-678 (2010)

W Xu, J Zhang, Research on the characteristics of digital venue environment. Open. Education Research 22(4), 95-102 (2016)

M Yi, Beijing declaration on building learning cities-lifelong learning for all: Promoting inclusion, prosperity and sustainability in cities. Journal of Continuing Higher Education 27(1), 2-5 (2014)

M Zhao, S Zhu, The problem domain and the development tendency of practice in workplace learning. Journal of Soochow University: Education Science Edition 3(4), 53-60 (2015)

T Zheng, X Ma, Design of learning environment_-Dialogue with professor Michael F. Hannafin. China. Educ. Technol. 2, 1-6 (2010)

P Zhou, Social Work of Community (Social Sciences Academic Press, Beijing, 2002)

Submit your manuscript to a SpringerOpen ${ }^{\circ}$ journal and benefit from:

- Convenient online submission

- Rigorous peer review

- Open access: articles freely available online

- High visibility within the field

- Retaining the copyright to your article

Submit your next manuscript at $>$ springeropen.com 